\title{
Influence of Sodium Alginate on Hypoglycemic Activity of Metformin Hydrochloride in the Microspheres Obtained by the Spray Drying
}

\author{
Marta Szekalska, Magdalena Wróblewska, Katarzyna Sosnowska, and Katarzyna Winnicka \\ Department of Pharmaceutical Technology, Medical University of Bialystok, Mickiewicza 2c, 15-222 Białystok, Poland \\ Correspondence should be addressed to Katarzyna Winnicka; kwin@umb.edu.pl
}

Received 23 March 2016; Accepted 27 April 2016

Academic Editor: Qiang Wei

Copyright (C) 2016 Marta Szekalska et al. This is an open access article distributed under the Creative Commons Attribution License, which permits unrestricted use, distribution, and reproduction in any medium, provided the original work is properly cited.

\begin{abstract}
Alginate microspheres with metformin hydrochloride were prepared by the spray drying method in order to improve residence time of drug in the stomach. Nine formulations (F1-F9) with various drug: polymer ratio $(1: 2,1: 1$, and 2:1) and different sodium alginate concentration $(1 \%, 2 \%$, and $3 \%)$ were evaluated for size, morphology, drug loading, Zeta potential, and swelling degree. In vitro drug release, mathematical release profile, and physical state of microspheres were also evaluated. Optimal formulation characterized by the highest drug loading was formulation F6 (drug:polymer ratio 2:1 and 2\% alginate solution). Based on glucose uptake in Saccharomyces cerevisiae cells and $\alpha$-amylase inhibition tests, it could be concluded that alginate microspheres enhance hypoglycemic activity of metformin hydrochloride evaluated in vitro. Designed microspheres are promising as alternative, multicompartment dosage form for metformin hydrochloride delivery.
\end{abstract}

\section{Introduction}

Sodium alginate (ALG) is nontoxic, biocompatible, and biodegradable polymer, which belongs to the group of polysaccharides naturally present in the seaweed $[1,2]$. ALG is composed of monomers of $\beta$-D-mannuronic acid and $\alpha$-L-guluronic acid residues joined together by (1-4) glycoside linkages. It is a biopolymer widely used for dietetic, biotechnology, cosmetic, and pharmaceutical industry [3]. Mucoadhesiveness and ability to gelate make ALG a promising excipient in the development of various dosage forms for modified drug delivery. In contact with acidic $\mathrm{pH}$, ALG cross-links and forms swollen polymer matrix which acts as a reservoir enabling sustained drug release $[4,5]$. Additionally, ALG is characterized by the ability to reduce body weight and to control glycemia in diabetic individuals by reduction after meal fluctuations of glucose concentrations, insulin secretion, decreasing of food intake, and delaying gastric emptying [6-8].

Metformin hydrochloride (MF) is an orally administered antidiabetic agent from biguanide group, which is the first line therapy to treat type 2 diabetes. Its hypoglycemic action includes decrease in the hepatic glucose production and in the intestinal glucose absorption and increase in glucose metabolism which, in consequence, lead to the reduction in plasma glucose concentration. In addition, MF decreases appetite and has effect on weight reduction and improvement of the lipid profile with no risk of hypoglycemia. MF is water soluble, but its bioavailability after oral administration in conventional dosage forms is only about $50 \%[9,10]$. Increase in the stomach residence time and the improvement in drug bioavailability might be achieved by mucoadhesive dosage forms. Mucoadhesive drug delivery systems through the intimate contact with the absorption surface enable prolonged residence time, better drug absorption, and enhanced bioavailability and they also permit decrease in the drug dosing frequency. Microspheres are multicompartment dosage forms which provide improved efficacy, reduced toxicity, and larger margin of safety in case of dosage form damage compared with traditional single unit formulations. Mucoadhesive polymer's matrix enables them to adhere to the mucous membranes and to remain for longer time period in the gastrointestinal tract [11, 12].

One of the most widely reported methods for preparing ALG microspheres with MF is emulsion-cross-linking and nonaqueous evaporation [13-16]; therefore, the aim of this 
research was to attempt to formulate for the first time ALG microspheres with MF by the new spray drying technique. Obtained microspheres were characterized for size, morphology, entrapment efficiency, drug loading, Zeta potential, and the in vitro MF release. The effects of the drug:polymer ratio and concentration of ALG solution on the properties of microspheres were also studied. Mucoadhesive properties of the microspheres were examined by using TA.XT.Plus Texture Analyzer and three different models of adhesive layer: gelatin disc, mucin gel, and porcine stomach mucosa. The physical state of microspheres was determined by differential scanning calorimetry (DSC). Additionally, the hypoglycemic properties of microspheres and the influence of ALG on MF activity were studied by determination of glucose uptake in Saccharomyces cerevisiae cells and by $\alpha$-amylase inhibition test.

\section{Experimental Section}

2.1. Materials. Metformin hydrochloride (MF) was obtained from Debao Fine Chemical CO (Henan, China). Sodium alginate (ALG) low viscosity $(2 \%, 100-300 \mathrm{cP})$, mucin type II, and gelatin type B from bovine skin were purchased from Sigma Aldrich (Steinheim, Germany). Potassium dihydrogen phosphate, sodium hydroxide, hydrochloric acid, methanol, propan-1,2-diol, acetonitrile, and starch pure soluble were obtained from Chempur (Piekary Śląskie, Poland). Glucose was obtained from Prolab (Nakło, Poland). Water was distilled and passed through a reverse osmosis system, MilliQ Reagent Water System (Billerica, USA). Porcine stomach mucosa from large white pigs weighting $\approx 200 \mathrm{~kg}$ was obtained from the veterinary service (Turośń Kościelna, Poland). Samples were stored at $-20^{\circ} \mathrm{C}$ and before the experiment were defrosted and cut into $5 \mathrm{~mm}$ in diameter and $2 \mathrm{~mm}$ thick pieces. Saccharomyces cerevisiae was purchased from Lesaffre (Wołczyn, Poland), acarbose was obtained from Bayer Pharma AG (Berlin, Germany), and $\alpha$-amylase was obtained from Polfa S. A. (Warsaw, Poland).

2.2. Formulation of Microspheres Containing MF. Microspheres were prepared using Mini Spray Dryer B-290 (Büchi, Flawil, Switzerland). The flow rate was set to $4.5 \mathrm{~mL} / \mathrm{min}$, relative spray rate was fixed to $37 \mathrm{~m}^{3} / \mathrm{h}$, and spray flow was fixed to $600 \mathrm{~L} / \mathrm{h}$. The inlet and outlet temperatures were established at $200^{\circ} \mathrm{C}$ and $96^{\circ} \mathrm{C}$, respectively. The parameters of the spray drying were optimized in a number of preliminary tests. ALG of different concentrations (1\%, 2\%, and 3\%) and different drug : polymer ratio $(1: 1,1: 2$, and $2: 1)$ was sprayed to obtain different formulations of microspheres (F1-F9).

\subsection{Characteristics of Microspheres}

2.3.1. Morphology and Size. Microspheres were analyzed by optical microscope (Motic BA400, Wetzlar, Germany) and by scanning electron microscope (SEM) (Hitachi S4200, Tokyo, Japan). Before imaging, samples were sputter-coated with gold in an argon atmosphere (Leica EM AC 2000, Wetzlar, Germany). The microspheres size distribution was studied using Zetasizer NanoZS90 (Malvern Instruments, Malvern, UK) by laser light-diffraction technique after suspending in propane-1,2-diol (propane-1,2-diol was used because in aqueous medium swelling and dissolving of microspheres were observed).

2.3.2. HPLC Analysis. The concentration of MF in the medium was determined by the HPLC system Agilent Technologies 1200 equipped with a G1312A binary pump, a G1316A thermostat, a G1379B degasser, and a G1315B diode array detector (Agilent, Waldbronn, Germany). Data collection and analysis were performed using Chemstation 6.0 software. Isocratic separation was achieved on Waters Spherisorb $^{\circledR} 5.0 \mu \mathrm{M}$ ODS $4.6 \times 250 \mathrm{~mm}, 5 \mu \mathrm{m}$ column (Waters Corporation, Milford, USA). Mobile phase was acetonitrile : methanol : phosphate buffer, pH 3.0 (20:20:60, $\mathrm{v} / \mathrm{v}$ ), the flow rate was $1.0 \mathrm{~mL} / \mathrm{min}$, and UV detection was performed at a wavelength of $240 \mathrm{~nm}$ [17]. The column temperature was maintained at $25^{\circ} \mathrm{C}$. For injection into the HPLC system, $20 \mu \mathrm{L}$ of sample was used. All reagents used for analysis were HPLC grade. The retention time of MF was $2.8 \mathrm{~min}$. Standard calibration curve was linear over the range of $1-100 \mu \mathrm{g} / \mathrm{mL}$ with the correlation coefficient $\left(R^{2}\right) 0.999$.

2.3.3. MF Loading and Percentage Yield. MF loading in the microspheres was determined by dissolving an accurately weighted amount of microspheres $(20 \mathrm{mg})$ in $10 \mathrm{~mL}$ of distilled water and agitating it for $24 \mathrm{~h}$ at $150 \mathrm{rpm}$ in a water bath [18]. The sample solution was further diluted and filtrated through $0.45 \mu \mathrm{m}$ cellulose acetate Millipore filters (Billerica, USA). The percentage yield of MF in the ALG microspheres was determined by using the following formula:

$$
L=\frac{Q_{\mathrm{m}}}{W_{\mathrm{m}}} \times 100,
$$

where $L$ is the percentage of drug loading, $Q_{m}$ is the drug loaded in the microspheres, and $W_{\mathrm{m}}$ is the weight of the microspheres. The mean drug encapsulation efficiency was calculated by the following equation:

$$
\mathrm{EE}=\frac{\mathrm{Q}_{\mathrm{a}}}{\mathrm{Q}_{\mathrm{t}}} \times 100,
$$

where EE is the percentage of encapsulation efficiency, $Q_{a}$ is the actual drug content, and $Q_{t}$ is the theoretical drug content.

Percentage production yield was calculated as the relationship of the achieved weight of the microspheres related to the entire amount of the theoretical weight of drug and polymer:

$$
Y=\frac{W_{\mathrm{m}}}{W_{\mathrm{t}}} \times 100,
$$

where $Y$ is the percentage production yield, $W_{\mathrm{m}}$ is the weight of microspheres, and $W_{\mathrm{t}}$ is the theoretical weight of drug and polymer.

2.3.4. Microspheres Porosity. Microspheres porosity was determined by using the solvent replacement method [19]. 
Dried microspheres were immersed overnight in absolute ethanol and weighed after excess ethanol on the surface was blotted. Then, porosity was calculated based on the following equation:

$$
P \%=\frac{\left(W_{W}-W_{D}\right)}{\rho \times V} \times 100,
$$

where $P \%$ is the porosity, $W_{D}$ is the weight of microspheres before immersion in absolute ethanol, $W_{W}$ is the weight of microspheres after immersion in absolute ethanol, $\rho$ is the density of absolute ethanol, and $V$ is the volume of microspheres.

2.3.5. Zeta Potential. Zeta potential measurements were performed using a Zetasizer NanoZS90 (Malvern Instruments, Malvern, UK). Before measurements, microspheres were suspended in propane-1,2-diol. Data was obtained from Zetasizer software 6.20.

2.3.6. Swelling Properties. Swelling properties were evaluated at $37 \pm 1^{\circ} \mathrm{C}$ in beakers containing $25 \mathrm{~mL}$ of $0.1 \mathrm{M} \mathrm{HCl}(\mathrm{pH} 1.2)$ and stirred at $100 \mathrm{rpm}$. The microspheres were periodically weighted at predetermined time intervals until a constant weight was obtained [20]. The swelling ratio was calculated by using the following formula:

$$
\mathrm{SR}=\frac{W_{\mathrm{S}}-W_{0}}{W_{0}} \times 100,
$$

where SR is the swelling ratio, $W_{0}$ is the initial weight of microspheres, and $W_{\mathrm{S}}$ is the weight of microspheres after swelling.

2.3.7. Mucoadhesiveness. Evaluation of mucoadhesiveness was performed using TA.XT.Plus Texture Analyzer (Stable Micro Systems, Godalming, UK) and three different models of mucoadhesive material: gelatin disc, mucin gel, and porcine stomach mucosa. Experimental parameters of the process were chosen during preliminary tests and set as follows: pretest speed $0.5 \mathrm{~mm} / \mathrm{s}$, test speed $0.1 \mathrm{~m} / \mathrm{s}$, contact time $180 \mathrm{~s}$, posttest $0.1 \mathrm{~mm} / \mathrm{s}$, and applied force $1 \mathrm{~N}$. Gelatin discs were prepared by pouring 30\% (w/w) aqueous solution into a Petri dish. Layer of mucin was prepared by absorbing $10 \%$ mucin gel on discs with cellulose fiber ( $5 \mathrm{~mm}$ in diameter). The tests were conducted at $37 \pm 1^{\circ} \mathrm{C}$. Adhesive layers were adhered to an upper probe and moisturized (excepted mucin) with $0.1 \mathrm{M} \mathrm{HCl}$ ( $\mathrm{pH}$ 1.2) [21]. The mucoadhesive properties were determined as the maximum detachment force $\left(F_{\max }\right)$ and the work of mucoadhesion $\left(W_{\mathrm{ad}}\right)$, calculated from the area under the force versus distance curve, expressed in $\mu \mathrm{J}$.

2.4. In Vitro MF Release. For the in vitro MF release test, apparatus type I (Erweka Dissolution tester type DT $600 \mathrm{HH}$, Heusenstamm, Germany) was used [22]. Microspheres were placed in the basket, immersed in $500 \mathrm{~mL}$ of $0.1 \mathrm{M} \mathrm{HCl}(\mathrm{pH}$ 1.2), and stirred at $50 \mathrm{rpm}$. In each study, the amount of microspheres equivalent to $500 \mathrm{mg}$ of MF was analyzed. Samples were withdrawn and filtered through $0.45 \mu \mathrm{m}$ cellulose acetate Millipore filters (Billerica, USA) at predetermined time intervals and replaced with fresh dissolution medium [23]. During the dissolution process, the temperature was maintained at $37 \pm 1^{\circ} \mathrm{C}$. The amount of released $\mathrm{MF}$ was analyzed by HPLC method (as described in Section 2.3.2).

2.5. Mathematical Modeling of MF Release Profile. MF release data were analyzed according to zero-order kinetic, firstorder kinetic, Higuchi model, Korsmeyer-Peppas equation, and Hixson-Crowell cube root law to characterize mechanism of the drug release. The constants of release kinetics and the regression coefficients $\left(R^{2}\right)$ were calculated from the slope of plots by linear regression analysis.

Zero-order kinetic is as follows:

$$
F=k \times t
$$

First-order kinetic is as follows:

$$
\ln F=k \times t .
$$

Higuchi model is as follows:

$$
F=k \sqrt{t}
$$

Korsmeyer-Peppas model is as follows:

$$
F=k t^{n}
$$

Hixson-Crowell model is as follows:

$$
1-(1-F)^{1 / 3}=k t
$$

where $F$ is the fraction of the drug release, $k$ is the release constant, and $t$ is the time. For the Korsmeyer-Peppas model, the fraction of drug remaining at time $t$ was determined for every time interval $\log \left(M_{t} / M_{\infty}\right)$ and plotted against the log of time $t$. The slope of the line was taken as the value of $n$, diffusional release exponent used for interpretation of release mechanism $[24,25]$.

2.6. Differential Scanning Calorimetry (DSC). DSC analysis of MF, ALG, and microspheres formulation F6 (with the highest drug loading) was performed using an automatic thermal analyzer system (DSC TEQ2000, TA Instruments, New Castle, USA). Each sample was precisely weighted (5 mg) and placed in sealed aluminium pan. An empty pan sealed was used as a reference. Temperature calibrations were performed using indium and zinc as standard. Samples were heated from $25^{\circ} \mathrm{C}$ to $200^{\circ} \mathrm{C}$ at scanning rate of $10^{\circ} \mathrm{C} / \mathrm{min}$ under nitrogen flow of $20 \mathrm{~mL} / \mathrm{min}$ [26].

\subsection{Evaluation of ALG Influence on MF Hypoglycemic Activity}

2.7.1. Glucose Uptake by Saccharomyces Cerevisiae Cells. Glucose uptake by Saccharomyces cerevisiae cells is often used model to in vitro study hypoglycemic activity [27-29]. Cells 
TABLE 1: Characteristics of MF loaded ALG microspheres (formulations F1-F9).

\begin{tabular}{|c|c|c|c|c|c|c|c|}
\hline Formulation & $\begin{array}{l}\text { Drug : polymer } \\
\text { ratio }\end{array}$ & $\begin{array}{l}\text { Zeta potential } \\
\quad(\mathrm{mV})\end{array}$ & $\begin{array}{l}\text { Production } \\
\text { yield (\%) }\end{array}$ & $\begin{array}{l}\text { Encapsulation } \\
\text { efficiency (\%) }\end{array}$ & $\begin{array}{c}\text { Percent } \\
\text { loading (\%) }\end{array}$ & $\begin{array}{l}\text { Mean diameter } \\
(\mu \mathrm{m})\end{array}$ & Porosity (\%) \\
\hline \multicolumn{8}{|c|}{$1 \%$ ALG solution } \\
\hline $\mathrm{F} 1$ & $1: 2$ & $-5.3 \pm 0.3$ & $57.1 \pm 1.6$ & $119.8 \pm 2.1$ & $39.9 \pm 1.7$ & $3.5 \pm 0.8$ & $73.39 \pm 2.3$ \\
\hline $\mathrm{F} 2$ & $1: 1$ & $-3.4 \pm 0.4$ & $86.1 \pm 2.4$ & $111.9 \pm 2.7$ & $55.6 \pm 3.4$ & $3.4 \pm 1.1$ & $67.02 \pm 4.2$ \\
\hline $\mathrm{F} 3$ & $2: 1$ & $-1.4 \pm 0.9$ & $85.9 \pm 1.4$ & $109.4 \pm 3.2$ & $72.9 \pm 1.6$ & $1.7 \pm 0.9$ & $60.71 \pm 3.5$ \\
\hline \multicolumn{8}{|c|}{$2 \%$ ALG solution } \\
\hline $\mathrm{F} 4$ & $1: 2$ & $-5.8 \pm 2.3$ & $61.8 \pm 1.5$ & $115.4 \pm 1.9$ & $38.4 \pm 2.2$ & $5.7 \pm 1.1$ & $75.04 \pm 2.5$ \\
\hline F5 & $1: 1$ & $-4.2 \pm 0.9$ & $68.0 \pm 1.3$ & $103.1 \pm 2.1$ & $51.5 \pm 3.6$ & $3.6 \pm 0.5$ & $65.55 \pm 2.4$ \\
\hline F6 & $2: 1$ & $-1.3 \pm 0.7$ & $61.7 \pm 2.1$ & $113.4 \pm 2.3$ & $75.6 \pm 1.5$ & $3.0 \pm 1.6$ & $61.81 \pm 3.7$ \\
\hline \multicolumn{8}{|c|}{$3 \%$ ALG solution } \\
\hline F7 & $1: 2$ & $-7.7 \pm 3.8$ & $68.9 \pm 1.1$ & $111.9 \pm 2.6$ & $37.3 \pm 3.9$ & $4.0 \pm 0.8$ & $72.97 \pm 3.5$ \\
\hline F8 & $1: 1$ & $-3.7 \pm 1.5$ & $58.9 \pm 1.4$ & $111.1 \pm 2.9$ & $55.7 \pm 3.9$ & $2.5 \pm 1.3$ & $60.88 \pm 2.9$ \\
\hline F9 & $2: 1$ & $-1.8 \pm 1.1$ & $45.0 \pm 2.1$ & $110.4 \pm 3.1$ & $73.6 \pm 7.5$ & $1.6 \pm 0.4$ & $59.70 \pm 2.5$ \\
\hline
\end{tabular}

were grown at $30 \pm 1^{\circ} \mathrm{C}$ in a bottom flask containing $500 \mathrm{~mL}$ of sterilized modified minimal medium $\mathrm{pH} 5.3$ for yeast growth $\left(0.5 \mathrm{~g} \mathrm{KH}_{2} \mathrm{PO}_{4}, 0.5 \mathrm{~g}\left(\mathrm{NH}_{4}\right)_{2} \mathrm{SO}_{4}, 0.5 \mathrm{~g} \mathrm{MgSO}_{4}, 1 \mathrm{~g}\right.$ yeast extract, and 10 g glucose) [30]. Cells growth started from a stationary preculture of about $10^{7} \mathrm{cfu} / \mathrm{mL}$. Then, cells were washed three times with distilled water and centrifugated (3000 $\times \mathrm{g}, 5 \mathrm{~min})$. The cytocrit was adjusted to $10 \%$ cells [31]. MF, microspheres placebo, and microspheres formulation F6 were added to $1 \mathrm{~mL}$ of various concentrations of glucose solution $(5,10$, and $25 \mathrm{mM})$ and incubated for $10 \mathrm{~min}$ at $37 \pm 1^{\circ} \mathrm{C}$. Reaction was started by adding $100 \mu \mathrm{L}$ of yeast suspension; then, mixture was vortexed and incubated at $37 \pm$ $1^{\circ} \mathrm{C}$ for $60 \mathrm{~min}$. After incubation, mixtures were centrifuged (2500 $\times$ g, $5 \mathrm{~min})$ and concentration of glucose remaining in the medium was estimated by using glucose assay kit (One Touch Select, Johnson \& Johnson, New Brunswick, USA) [27].

2.7.2. $\alpha$-Amylase Inhibition. $\alpha$-Amylase inhibition was evaluated by modified method based on the starch iodide reaction. Mixture composed of $1 \mathrm{~mL} 0.02 \mathrm{M}$ sodium phosphate buffer ( $\mathrm{pH}$ 6.9), 5 units of $\alpha$-amylase solution, and examined samples (microspheres placebo, microspheres F6, and MF) was incubated at $37 \pm 1^{\circ} \mathrm{C}$ for $10 \mathrm{~min}$. Then, $1 \mathrm{~mL}$ of starch solution $(1 \%, \mathrm{w} / \mathrm{v})$ was added and mixture was incubated at $37 \pm 1^{\circ} \mathrm{C}$ for $15 \mathrm{~min}$. To stop the enzymatic reaction, $1 \mathrm{M}$ $\mathrm{HCl}(20 \mu \mathrm{L})$ was added, followed by the addition of $20 \mu \mathrm{L}$ of iodide reagent ( $5 \mathrm{mM} \mathrm{I}_{2}$ and $5 \mathrm{mM} \mathrm{KI}$ ) [32-34]. To eliminate the absorbance produced by analyzed substances, appropriate controls were also included. The triiodide anion with iodide reagent creates complexes with starch, producing an intense blue color. The absorbance was measured spectrophotometrically at $586 \mathrm{~nm}$ using Genesys 10S UV-Vis Spectrophotometer (Thermo Scientific, Madison, USA). The activity of examined samples was compared with acarbose (3, 5, and $10 \mathrm{mg})$, a well established $\alpha$-amylase inhibitor [35]. Concentration of starch was calculated according to the calibrating curve. The control reaction (without examined substances) represented $100 \%$ of enzyme activity. $\alpha$-Amylase inhibition was assessed using the following formula:

$$
\% \mathrm{IA}=\frac{\left(C_{\mathrm{S}}-C_{\mathrm{C}}\right)}{C_{\mathrm{S}}} \times 100,
$$

where IA is the percent of $\alpha$-amylase inhibition, $C_{\mathrm{C}}$ is the concentration of starch in the control reaction, and $C_{S}$ is the concentration of starch in the test sample [34-36].

2.8. Statistical Analysis. Quantity variables were expressed as the mean and standard deviation. Statistical analysis was performed using nonparametric Kruskal-Wallis test and conducted by Statistica 10.0 software (StatSoft, Tulsa, USA). Differences between groups were considered to be significant at $p<0.05$.

\section{Results and Discussion}

3.1. Microspheres Morphology, Size, and Surface Charge Anal$y$ sis. Spray drying is a relatively simple, one-step process which includes spray drying of drug solution or suspension in a stream of gas and depends on several parameters, for example, atomization devices, aspirator and feed rate, drying temperature, spray air flow, and properties of the drying material [37]. This method enables entrapment of both hydrophilic and hydrophobic drugs in polymer matrix and compared to other techniques (emulsificationprecipitation, emulsification-cross-linking, ionotropic gelation, solvent evaporation, and coacervation) it might be used in both laboratory and industrial scale. Moreover, it is characterized by the possibility of precisely controlling production parameters, high production yield (40-80\%), and encapsulation efficiency (up to 100\%) [37-40]. It was shown that formulated microspheres were characterized by relatively narrow size distribution and MF loading in all formulations was in the range between $37.3 \pm 3.8 \%$ and $75.6 \pm 1.4 \%$ (Table 1).

Drug: polymer ratio is a key factor influencing the characteristics of microspheres. The minimum MF loading was 


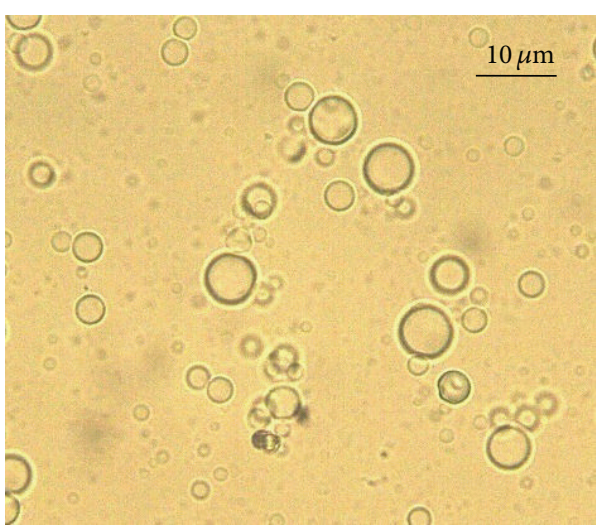

(a)

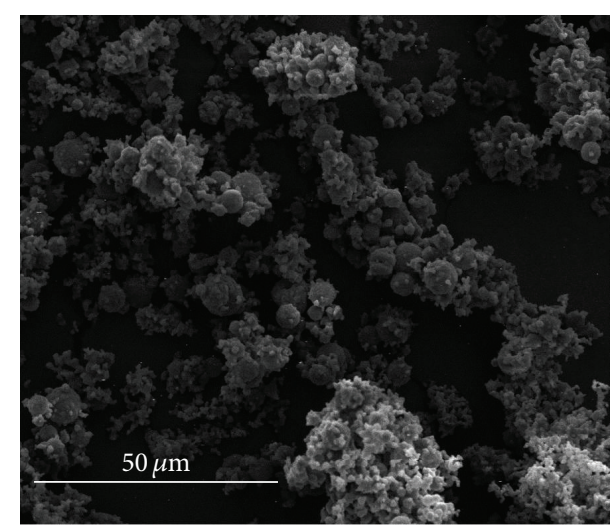

(b)

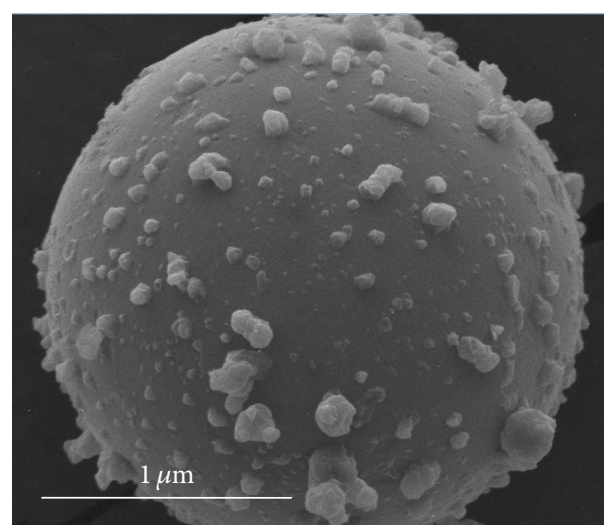

(c)

FIGURE 1: Representative images of microspheres formulation F6 under magnifications $\times 40$ (a), $\times 2000$ (b), and $\times 10000$ (c).

observed in formulations F7, F4, and F1 with drug: polymer ratio $1: 2(37.3 \pm 3.9 \%, 38.4 \pm 2.2 \%$, and $39.9 \pm 1.7 \%$, resp. $)$. The maximum drug loading was in formulations F6, F9, and F3 $(75.6 \pm 1.5 \%, 73.6 \pm 7.5 \%$, and $72.9 \pm 1.6 \%)$ when drug : polymer ratio was $2: 1$. Interestingly, concentration of ALG solution had no significant impact on microspheres characteristics. Application of more concentrated solution of ALG (3\%) did not result in higher production yield and diameter of obtained microspheres. It is worth noting that encapsulation efficiency in all microspheres was higher than $100 \%$. It can be explained by a partial loss of the polymer during the preparation of microspheres, which decreased the theoretical polymer mass and changed the theoretical drug content to values higher than the previewed ones [41]. All formulations of microspheres had spherical shape. The morphology of microspheres F6 (with the highest MF loading) examined by optical and scanning electron microscopy is presented in Figure 1.

Zeta potential is an important parameter related to the stability of colloidal dispersions [42]. Zeta potential values of designed microspheres varied between $-1.3 \pm 0.7$ and $-7.7 \pm$ $3.8 \mathrm{mV}$ as shown in Table 1 (compared to $-15.9 \mathrm{mV}$ for ALG microspheres placebo). Although ALG is negatively charged, values of Zeta potential of microspheres with MF were close to zero. It is probably caused by complex formation between the polyanionic ALG and oppositely charged MF. Formulation F6 (with the highest drug loading) was characterized by the lowest Zeta potential value.

3.2. Swelling and Mucoadhesive Properties. Mechanism of mucoadhesion is directly connected with water uptake into the polymer matrix, swelling, and gel layer formation [43]. Swelling is mainly attributed to the hydration of the hydrophilic groups of ALG, where water penetrates inside the microspheres and fills the inert pores among polymer chains. ALG swelling and dissolution are $\mathrm{pH}$ dependent. At acidic $\mathrm{pH}$, as a result of reduction of the electrical repulsion between the negatively charged ALG molecules and positively charged ions in the medium, polymer is protonated and creates insoluble form of alginic acid [44, 45]. After protonation of carboxylic acid groups, the polymer shrinks, absorption of water is decreased, and in consequence swelling degree decreases [43]. The swelling profiles, represented as the swelling ratio (SR) versus time, are reported in Figure 2.

Figure 2 illustrates the swelling properties of the designed microspheres in $0.1 \mathrm{M} \mathrm{HCl}$ ( $\mathrm{pH} 1.2)$ at different time intervals. All the curves gave linear increase, indicating a loosening of the matrix with the creation of larger pores [46]. The results indicated that formulations of microspheres swelled 

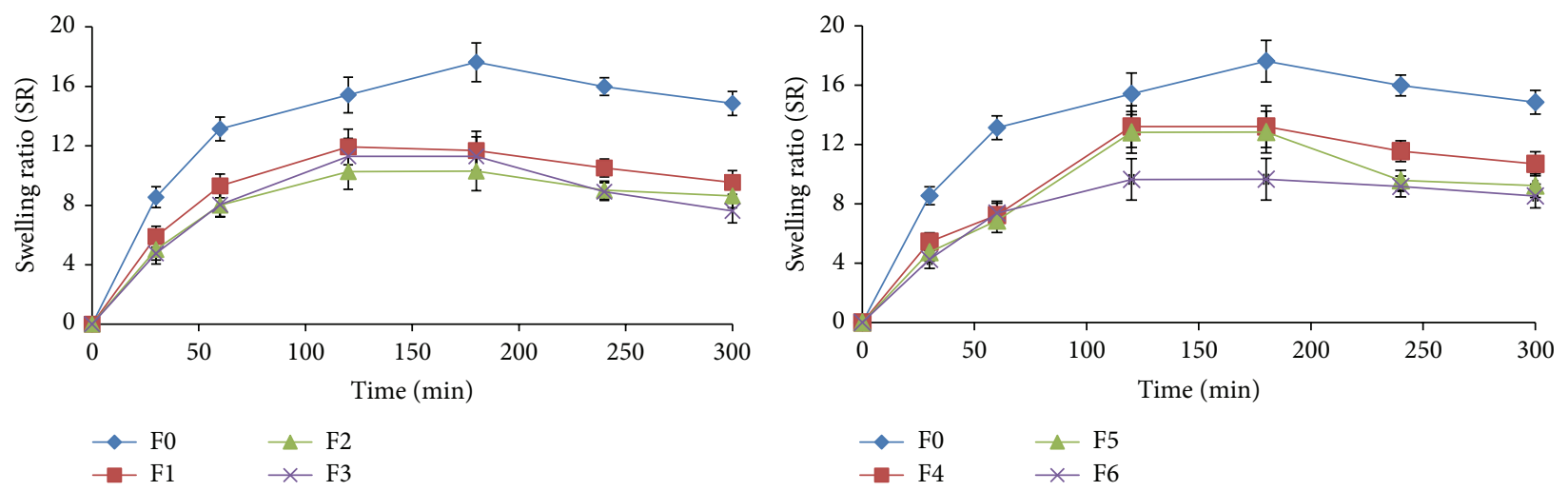

(a)

(b)

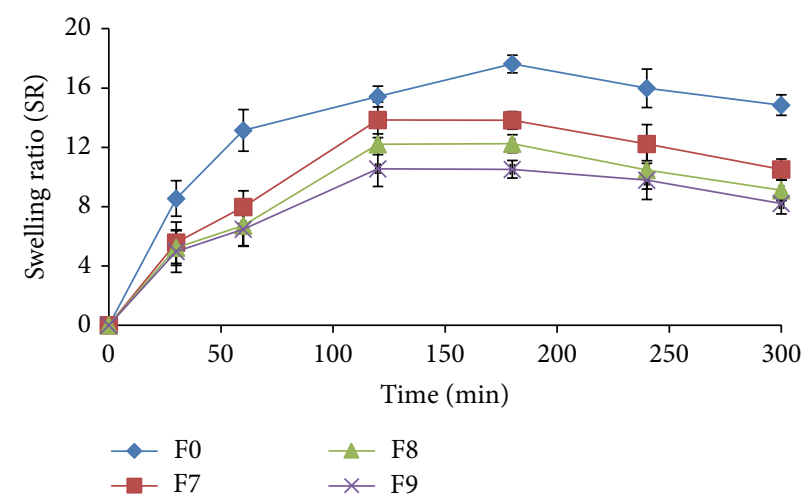

(c)

FIGURE 2: Swelling ratio (SR) of microspheres placebo (F0) and formulations F1-F3 (a), F4-F6 (b), and F7-F9 (c).

gradually. Obtained curves showed an initial rapid increase within 30 min of the experiment due to the entry of water via metastable pores known as hysteresis of swelling mechanism and reached the highest value after $120 \mathrm{~min}$ for formulations F1-F9 and after $180 \mathrm{~min}$ for microspheres placebo. Formulation F7 (with the lowest MF content) showed the highest swelling ratio, while microspheres F6 (with the highest MF loading) attained lower value of SR. Swelling in acidic $\mathrm{pH}$ as a result of osmosis caused by unbound carboxyl groups enables forming a swollen gel and surface erosion, which results in disintegration of microspheres and sustained MF release.

The mucoadhesive drug delivery systems increase drug residence time and in consequence improve its bioavailability. ALG as polyanionic polymer is characterized by higher bioadhesive properties than polycationic (chitosan, poly(llysine)) or nonionic polymers (macrogol, hypromellose and polyvinyl alcohol) $[47,48]$. Mechanism of ALG mucoadhesion is defined by interaction between carboxyl groups of polymer and mucin through electrostatic adsorption, van der Waals, and hydrogen bonds. The surface of mucin is positively charged and its flexible backbone chains enable interaction with ALG carboxyl groups. Initially, contact (wetting) between polymer and mucus and, subsequently, polymer swelling make the polymer strands relax [47, 48]. This is followed by the penetration of ALG into the mucus network and finally the formation of secondary chemical bonds between the mucus and the polymer. The influence of MF on the mucoadhesive properties of ALG microspheres is shown in Table 2.

The mucoadhesive properties were presented as maximum detachment force $\left(F_{\max }\right)$ and work of adhesion $\left(W_{\mathrm{ad}}\right)$ and as the adhesive layers gelatin discs, mucin gel, and porcine stomach mucosa were used. Porcine stomach mucosa model is often used in order to imitate in vivo conditions [49]. It was shown that ALG microspheres readily adhered to all tested mucoadhesive materials and that detachment force and work of adhesion increased when drug loading was decreased. When gelatin was used as adhesive layer, relatively large maximum detachment force and small values of the work of adhesion were observed. This fact might indicate that microspheres adhere to this layer for very short time, forming only weak bonds between gelatin and alginate. The lower mucoadhesiveness of microspheres F3, F6, and F9 is probably due to the high MF content causing disturbances in ALG gel structure. It is worth noting that significant $(p<0.05)$ differences of detachment force and work of adhesion values between gelatin and porcine stomach mucosa were observed; therefore, it might be suggested that mucin gel is a better substitute of mucous membrane.

Moreover, the obtained results indicate that there is direct correlation between mucoadhesive properties and SR. The highest values of $F_{\max }(0.9 \pm 0.1)$ and $W_{\text {ad }}(768.2 \pm 5.4)$ were observed for formulation F7 with the highest SR value. 
TABLE 2: Mucoadhesive properties of microspheres placebo (F0) and microspheres formulations F1-F9.

\begin{tabular}{|c|c|c|c|c|c|c|}
\hline \multirow{3}{*}{ Formulation } & \multicolumn{6}{|c|}{ Type of adhesive layer } \\
\hline & \multicolumn{2}{|c|}{ Gelatin } & \multicolumn{2}{|c|}{ Mucin } & \multicolumn{2}{|c|}{ Porcine stomach mucosa } \\
\hline & $F_{\max }[\mathrm{N}]^{*}$ & $W_{\text {ad }}[\mu \mathrm{J}]^{* *}$ & $F_{\max }[\mathrm{N}]^{*}$ & $W_{\mathrm{ad}}[\mu \mathrm{J}]^{* *}$ & $F_{\max }[\mathrm{N}]^{*}$ & $W_{\text {ad }}[\mu J]^{* *}$ \\
\hline F0 & $0.9 \pm 0.3$ & $362.9 \pm 1.8$ & $1.1 \pm 3.7$ & $583.4 \pm 1.5$ & $1.3 \pm 1.3$ & $779.5 \pm 2.4$ \\
\hline $\mathrm{F} 1$ & $0.5 \pm 0.2$ & $237.5 \pm 1.0$ & $0.5 \pm 0.2$ & $275.1 \pm 1.6$ & $0.7 \pm 0.1$ & $428.0 \pm 2.6$ \\
\hline $\mathrm{F} 2$ & $0.5 \pm 0.2$ & $203.0 \pm 0.6$ & $0.5 \pm 0.3$ & $207.2 \pm 0.5$ & $0.7 \pm 0.2$ & $360.9 \pm 1.3$ \\
\hline F3 & $0.4 \pm 0.3$ & $179.5 \pm 0.4$ & $0.5 \pm 0.4$ & $179.5 \pm 0.1$ & $0.7 \pm 0.1$ & $272.3 \pm 0.5$ \\
\hline $\mathrm{F} 4$ & $0.5 \pm 0.2$ & $392.8 \pm 2.1$ & $0.6 \pm 0.2$ & $410.0 \pm 2.8$ & $0.8 \pm 0.2$ & $681.6 \pm 3.9$ \\
\hline F5 & $0.4 \pm 0.2$ & $264.0 \pm 0.3$ & $0.6 \pm 0.3$ & $367.7 \pm 1.5$ & $0.7 \pm 0.3$ & $560.3 \pm 4.1$ \\
\hline F6 & $0.5 \pm 0.2$ & $238.3 \pm 0.5$ & $0.6 \pm 0.3$ & $342.3 \pm 2.9$ & $0.6 \pm 0.2$ & $467.5 \pm 1.7$ \\
\hline F7 & $0.5 \pm 0.3$ & $319.4 \pm 1.5$ & $0.6 \pm 0.2$ & $501.0 \pm 3.1$ & $0.9 \pm 0.1$ & $768.2 \pm 5.4$ \\
\hline F8 & $0.5 \pm 0.2$ & $303.7 \pm 1.3$ & $0.7 \pm 0.4$ & $489.6 \pm 3.8$ & $0.8 \pm 0.2$ & $692.1 \pm 4.6$ \\
\hline F9 & $0.4 \pm 0.1$ & $234.2 \pm 0.6$ & $0.7 \pm 0.3$ & $441.8 \pm 2.3$ & $0.6 \pm 0.3$ & $657.7 \pm 4.3$ \\
\hline
\end{tabular}

${ }^{*}$ Maximum detachment force and ${ }^{* *}$ work of adhesion.

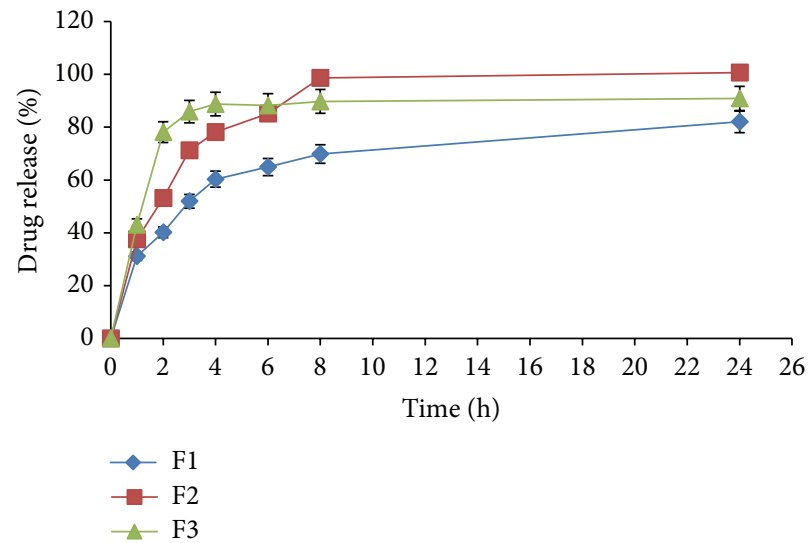

(a)

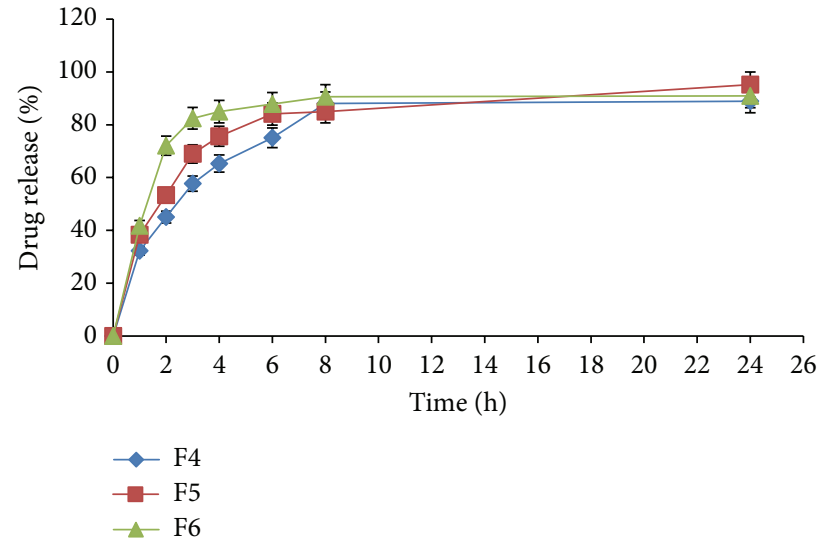

(b)

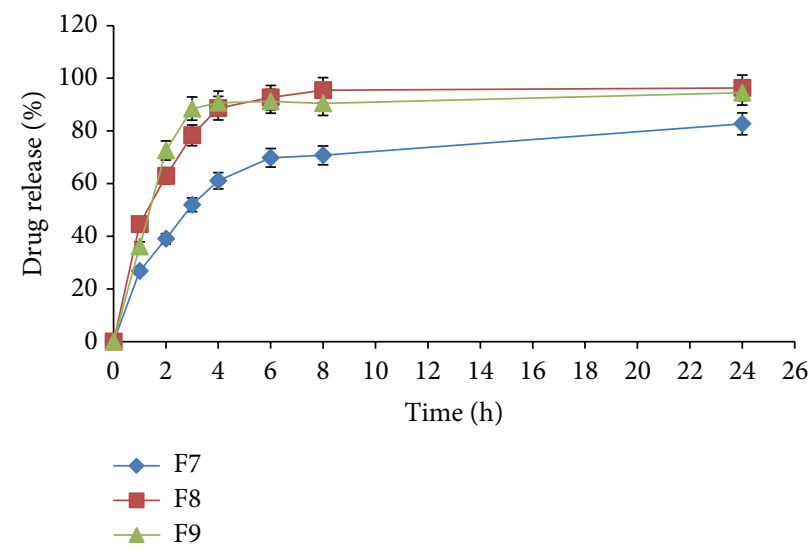

(c)

Figure 3: MF release from microspheres formulations F1-F3 (a), F4-F6 (b), and F7-F9 (c), $n=3$.

3.3. In Vitro $M F$ Release. The release profiles of MF from microspheres formulations F1-F9 are shown in Figure 3. In all formulations, the release profile showed a burst effect, which is the first phase of the drug release and occurs due to the free MF binding at the microparticles surface. The highest burst effect was observed in formulation F6, with the highest drug loading; after $30 \mathrm{~min}, 41.7 \pm 0.4 \%$ of MF was released. At acidic pH, ALG swells and creates gelling alginic acid matrix, which prevents disintegration of microspheres and controls water penetration inside the microsphere structure. Formulations F1, F4, and F7, with the lowest MF content, were characterized by the higher swelling ratio and ensured 
TABLE 3: Models of MF release from microspheres formulations F1-F9.

\begin{tabular}{|c|c|c|c|c|c|c|c|c|c|c|c|}
\hline \multirow{2}{*}{ Formulation } & \multicolumn{2}{|c|}{$\begin{array}{l}\text { Zero-order } \\
\text { kinetics }\end{array}$} & \multicolumn{2}{|c|}{ First-order kinetics } & \multicolumn{2}{|c|}{ Highuchi model } & \multicolumn{3}{|c|}{ Korsmeyer-Peppas model } & \multicolumn{2}{|c|}{$\begin{array}{c}\text { Hixson-Crowell } \\
\text { model }\end{array}$} \\
\hline & $R^{2}$ & $K$ & $R^{2}$ & K & $R^{2}$ & $K$ & $R^{2}$ & K & $n$ & $R^{2}$ & K \\
\hline $\mathrm{F} 1$ & 0.92 & 1.67 & 0.97 & 0.17 & 0.98 & 22.98 & 0.94 & 0.31 & 0.08 & 0.96 & 0.18 \\
\hline $\mathrm{F} 2$ & 0.86 & 1.68 & 0.98 & 0.55 & 0.95 & 29.37 & 0.88 & 0.34 & 0.08 & 0.94 & 0.58 \\
\hline F3 & 0.41 & 4.07 & 0.59 & 0.18 & 0.56 & 16.82 & 0.51 & 0.27 & 0.11 & 0.52 & 0.16 \\
\hline $\mathrm{F} 4$ & 0.87 & 6.69 & 0.95 & 0.22 & 0.96 & 25.03 & 0.90 & 0.32 & 0.19 & 0.94 & 0.22 \\
\hline F5 & 0.82 & 6.55 & 0.95 & 0.13 & 0.93 & 25.15 & 0.86 & 0.32 & 0.17 & 0.95 & 0.27 \\
\hline F6 & 0.52 & 4.62 & 0.73 & 0.21 & 0.66 & 18.76 & 0.59 & 0.28 & 0.12 & 0.65 & 0.19 \\
\hline F7 & 0.90 & 7.34 & 0.93 & 0.22 & 0.96 & 27.11 & 0.91 & 0.33 & 0.22 & 0.91 & 0.23 \\
\hline F8 & 0.70 & 6.01 & 0.93 & 0.37 & 0.84 & 23.64 & 0.78 & 0.31 & 0.14 & 0.86 & 0.29 \\
\hline F9 & 0.45 & 5.15 & 0.66 & 0.25 & 0.60 & 21.33 & 0.58 & 0.31 & 0.14 & 0.58 & 0.22 \\
\hline
\end{tabular}

$R^{2}$ : correlation coefficient, $K$ : release constant, and $n$ : the release exponent.

sustained drug release; after $8 \mathrm{~h}$ of the study, the amount of released MF was $82.6 \pm 1.6 \%, 88.9 \pm 2.2 \%$, and $89.1 \pm 3.2 \%$, respectively.

Afterwards, MF release profiles were fitted to zero-order and first-order equations and Higuchi, Korsmeyer-Peppas, and Hixson-Crowell models (Table 3).

In the Highuchi model, the best fit curve with $R^{2}(0.98)$ was observed for formulation F1. It was also noticed that mechanism of MF release from formulations F1, F2, F4, F5, and F7 was diffusion controlled first-order kinetics as the plots showed higher regression correlation coefficient. However, based on Korsmeyer-Peppas equation in case of sphere shape microspheres, the value of diffusional exponent $n \geq 0.85$ means that drug release is independent of time (case II transport), while value $n \leq 0.43$ means that release is controlled by Fickian diffusion. A value between 0.43 and 0.85 indicates combination of diffusion and swelling mechanism. The obtained values of diffusion exponent from 0.08 to 0.22 confirm diffusion as mechanism of MF release. The high values of $R^{2}$ in the Hixson-Crowell model indicate that this equation can also describe MF release and suggest that it was controlled also by disintegration process of the microspheres. The Hixson-Crowell cube root law describes the release from the systems, where drug release depends on the change in surface area and diameter of the particles with time and it is mainly applied to systems which are subjected to dissolution or erosion processes. In this case, MF release rate is limited by the microspheres erosion. The obtained data have shown that MF release from ALG microspheres is complex and includes simultaneously erosion and diffusion mechanism. MF release can be controlled by water penetration, responsible for polymer hydration, erosion of microspheres, and drug diffusion $[50,51]$.

3.4. Differential Scanning Calorimetry (DSC). DSC is an important tool to obtain information about possible interactions between drug and polymer, according to the appearance, shift, or disappearance of endothermic or exothermic peaks. Thermograms of MF, ALG, microspheres placebo, and

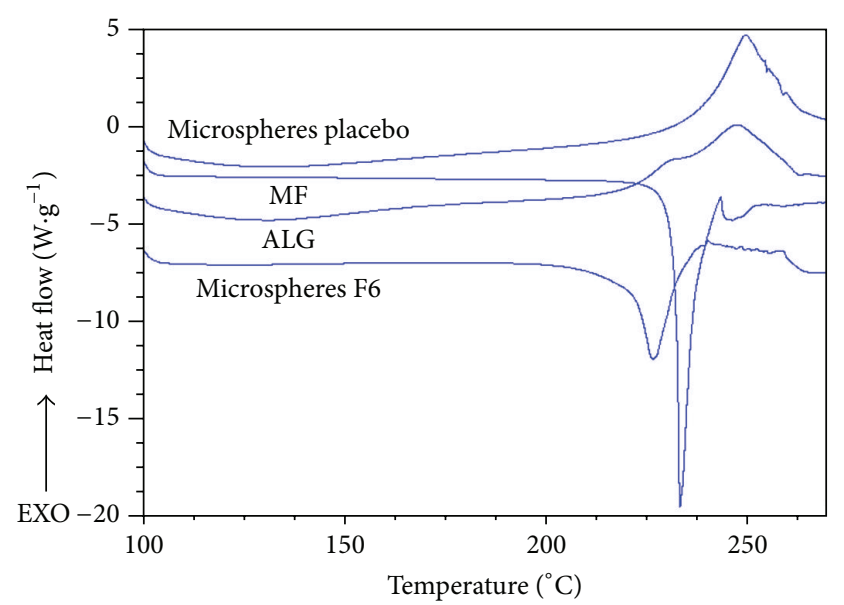

FIGURE 4: DSC thermograms of sodium alginate (ALG), metformin hydrochloride $(\mathrm{MF})$, microspheres placebo, and microspheres formulation F6.

microspheres formulation F6 (with the highest MF loading) are shown in Figure 4.

Under the experimental conditions, a sharp endothermic peak for pure $\mathrm{MF}$ was observed at $233.02^{\circ} \mathrm{C}$ corresponding to its melting point. Thermogram of microspheres formulation F6 has shown that peak of MF did not shift significantly $\left(226.55^{\circ} \mathrm{C}\right)$. Lowering of MF melting point in microspheres might be due to its mixing with ALG, which lowered the purity of each component; MF crystallinity was reduced and the drug might convert into the amorphous form. In the DSC thermogram, a small endothermic peak of ALG at $129.55^{\circ} \mathrm{C}$, attributed to the dehydration process, and strong exothermic peak at $247.80^{\circ} \mathrm{C}$, corresponding to the decomposition of the polymer, were observed. Melting peak of ALG $\left(129.27^{\circ} \mathrm{C}\right)$ was not detected in microspheres F6, which might suggest that ALG has dehydrated during the spray drying process [52].

3.5. Influence of ALG on MF Hypoglycemic Activity. Type 2 diabetes is a chronic metabolic disorder characterized by 
TABLE 4: In vitro glucose uptake by yeast cells incubated with microspheres placebo, microspheres $\mathrm{F} 6$, and metformin hydrochloride (MF).

\begin{tabular}{lccc}
\hline & \multicolumn{3}{c}{$\begin{array}{c}\text { Concentration of glucose }(\mathrm{mM}) \\
\text { remaining in the medium }\end{array}$} \\
& $5 \mathrm{mM}$ glucose & $10 \mathrm{mM}$ glucose & $20 \mathrm{mM}$ glucose \\
\hline $\begin{array}{l}\text { Control* } \\
\text { Microspheres } \\
\text { placebo }\end{array}$ & $3.79 \pm 1.67$ & $7.48 \pm 0.72$ & $14.72 \pm 1.32$ \\
$\begin{array}{l}\text { Microspheres } \\
\text { F6 }\end{array}$ & $1.65 \pm 2.79$ & $3.13 \pm 1.69$ & $6.51 \pm 1.01$ \\
MF $^{* *}$ & $1.22 \pm 0.18$ & $1.50 \pm 0.23$ & $3.91 \pm 0.69$ \\
\hline
\end{tabular}

${ }^{*}$ Suspension of Saccharomyces cerevisiae cells in glucose solution; ${ }^{* *} \mathrm{MF}$ was used in an amount $(10 \mathrm{mg})$ corresponding to its loading in microspheres formulation F6.

high level of blood glucose, which may lead to damage of the body organs [53]. Uncontrolled hyperglycemia can lead to the development of complications, such as dysfunction of blood vessels (retinopathy and neuropathy) and nervous system, and increasing the risk of cardiovascular diseases [54-56]. Although many antidiabetic drugs are available, most of them possess serious side effects or do not provide satisfactory glucose control. Therefore, many studies focus on the development of novel dosage forms for antidiabetic drugs. Hypoglycemic effect can be studied in vitro using a variety of models, which play a very important role as initial screening tools in the evaluation of antidiabetic activity of drugs and new dosage forms. To determine hypoglycemic activity of ALG microspheres with MF and to evaluate influence of ALG on MF hypoglycemic activity, glucose uptake by Saccharomyces cerevisiae cells and $\alpha$-amylase inhibition tests were performed.

3.5.1. Glucose Uptake by Saccharomyces Cerevisiae Cells. Polysaccharides can influence intestinal glucose absorption and the mechanism of this action includes forming a viscous gel which may slow the access of glucose to the epithelium, thereby decreasing postprandial glucose blood concentration. Viscous gel may also delay gastric emptying, slow down carbohydrate uptake, and retard carbohydrate access to digestive enzymes which may contribute to the postprandial effect $[57,58]$. Glucose uptake by Saccharomyces cerevisiae cells is complex process based on facilitated diffusion and controlled by multiple hexose transporters (Hxts) [59]. Roy et al. demonstrated that mechanism of glucose transport by Hxts is similar to human glucose transporters (GLUTs) [60]. As GLUT-2 is localized in the intestinal mucosa and it is responsible for monosaccharides absorption into the bloodstream [61], determination of glucose transport across the Saccharomyces cerevisiae cell membranes has been receiving attention as alternative method for the in vitro hypoglycemic effect evaluation. The amount of glucose remaining in the medium after incubation of Saccharomyces cerevisiae cells with different glucose concentrations $(5,10$, and $20 \mathrm{mM})$ and microspheres placebo, microspheres formulation F6, and MF is presented in Table 4.
Obtained results indicate that MF significantly increased glucose uptake by Saccharomyces cerevisiae cells compared to the control sample. The uptake of glucose by Saccharomyces cerevisiae cells incubated with formulation F6 was lower than that by cells incubated with pure MF. This effect was observed at all examined glucose concentrations $(5,10$, and $20 \mathrm{mM})$. In case of $10 \mathrm{mM}$ glucose solution, concentration of glucose remaining in the medium was $3.13 \pm 1.69 \mathrm{mM}$ for microspheres $\mathrm{F} 6,1.50 \pm 0.23 \mathrm{mM}$ for pure MF, and $9.01 \pm 1.61 \mathrm{mM}$ for microspheres placebo. The highest glucose uptake inhibition was observed when Saccharomyces cerevisiae cells were incubated with microspheres placebo, which suggests that pure ALG demonstrates the highest intestinal glucose absorption inhibitory potential.

3.5.2. $\alpha$-Amylase Inhibition. Therapeutic strategy of hyperglycemia in the treatment of type 2 diabetes involves decreasing the postprandial glucose concentration in the blood [53]. $\alpha$-Amylase is an intestinal enzyme which plays an important role in the carbohydrate digestion. It hydrolyses $\alpha$-bonds of polysaccharides (such as glycogen and starch) to glucose and maltose. Inhibitors of this enzyme delay carbohydrate digestion through binding to $\alpha$-bonds and prevent decomposition of polysaccharides into mono- and disaccharides $[62,63]$. This action prolongs the overall time for carbohydrate digestion and results in a reduction of glucose absorption. Consequently, inhibition of $\alpha$-amylase reduces the postprandial fluctuations of blood glucose and decreases glycemic index of food [64-66]. It was shown that seaweeds can reduce activity of $\alpha$-amylase; therefore, impact of ALG microspheres with MF on enzyme activity was studied. The results of $\alpha$-amylase inhibition test are illustrated in Figure 5.

Inhibition of enzyme activity by microspheres F6 was associated with the amount of polymer; samples containing higher amount of ALG more effectively inhibited $\alpha$ amylase. The values of enzyme inhibition were ranged from $5.35 \pm 0.32 \%$ (for $7.56 \mathrm{mg}$ of $\mathrm{MF}$ ) to $63.82 \pm 2.83 \%$ (for $10 \mathrm{mg}$ of microspheres placebo) (Figure 5(a)). Microspheres formulation F6 was characterized by stronger $\alpha$ amylase inhibition activity $(36.34 \pm 2.45 \%)$ compared to pure MF.

\section{Conclusions}

MF release and mucoadhesive properties of ALG microspheres obtained by the spray drying can be altered by varying the drug : polymer ratio. Optimal formulation characterized by the highest drug loading was formulation F6 (drug:polymer ratio $2: 1$ and $2 \%$ alginate solution). All microspheres possessed swelling and mucoadhesive properties depending on drug and polymer content. The release profile of MF from microspheres was prolonged and controlled by Fickian diffusion. Based on the in vitro hypoglycemic activity evaluation, it can be concluded that ALG microspheres enhance activity of MF. It was observed that ALG affects inhibition of glucose uptake in Saccharomyces 


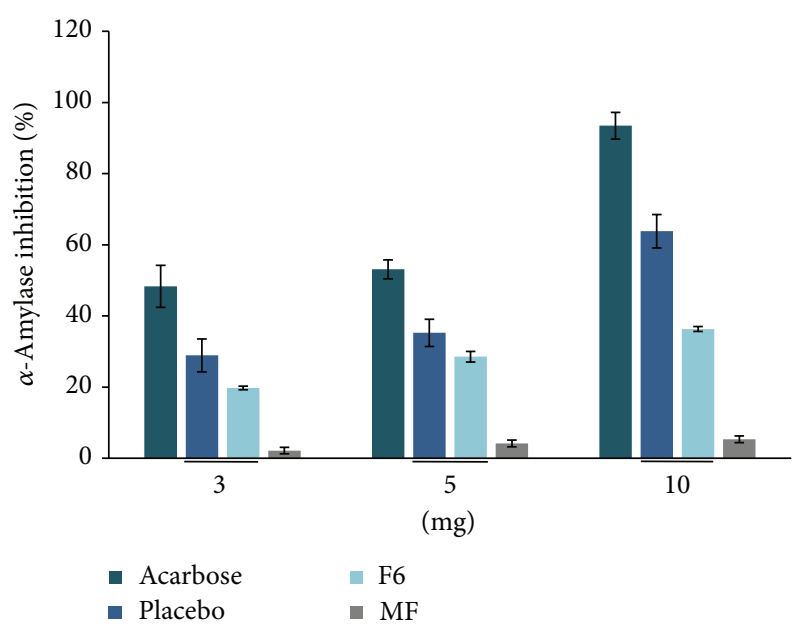

(a)

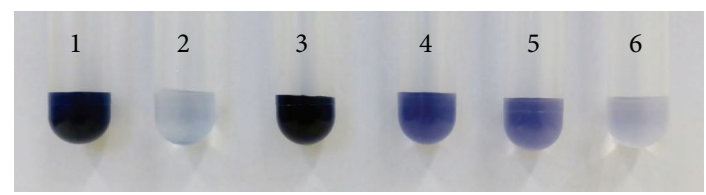

(b)

Figure 5: The effect of microspheres placebo (placebo), microspheres formulation F6 (F6), and metformin hydrochloride (MF) in an amount corresponding to its loading in microspheres formulation F6 $(2.27 \mathrm{mg}, 3.78 \mathrm{mg}$, and $7.56 \mathrm{mg}$, resp.) on the in vitro $\alpha$-amylase inhibition (a), and representative images of reactive mixture: without $\alpha$-amylase (1), with $\alpha$-amylase (2), with acarbose (3), with microspheres placebo (4), with microspheres formulation F6 (5), and with $7.56 \mathrm{mg}$ of pure metformin hydrochloride (in an amount corresponding to its loading in microspheres formulation F6) (6) (b), $n=3$.

cerevisiae cells and reduces $\alpha$-amylase activity. As inhibition of intestinal glucose absorption is crucial in type 2 diabetes treatment, ALG might be valuable excipient in designing dosage forms with MF. Designed microspheres seem to be promising as alternative, multicompartment dosage form for metformin hydrochloride delivery. However, in vivo evaluation of ALG influence on hypoglycemic activity of MF in the microspheres is necessary and will be described in a due course.

\section{Competing Interests}

The authors declare no competing interests.

\section{Acknowledgments}

This research was conducted with the use of equipment purchased by the Medical University of Białystok as part of the OP DEP 2007-2013, Priority Axis I.3, Contract no. POPW.01.03.00-20-008/09, and supported by Medical University of Białystok Grant (no. N/ST/MN/16/001/2215).

\section{References}

[1] K. N. Sachan, S. Pushkar, A. Jha, and A. Bhattcharya, "Sodium alginate: the wonder polymer for controlled drug delivery," Journal of Pharmacy Research, vol. 2, no. 8, pp. 1191-1199, 2009.

[2] A. Sosnik, "Alginate particles as platform for drug delivery by the oral route: state-of-the-art," ISRN Pharmaceutics, vol. 2014, Article ID 926157, 17 pages, 2014.

[3] H. H. Tønnesen and J. Karlsen, "Alginate in drug delivery systems," Drug Development and Industrial Pharmacy, vol. 28, no. 6, pp. 621-630, 2002.

[4] H. K. Solanki and D. A. Shah, "Formulation optimization and evaluation of probiotic Lactobacillus sporogenes-loaded sodium alginate with carboxymethyl cellulose mucoadhesive beads using design expert software," Journal of Food Processing, vol. 2016, Article ID 6041671, 14 pages, 2016.

[5] A. Ahmadi, S. Z. Moghadamtousi, S. Abubakar, and K. Zandi, "Antiviral potential of algae polysaccharides isolated from marine sources: a review," BioMed Research International, vol. 2015, Article ID 825203, 10 pages, 2015.

[6] M. G. Jensen, M. Kristensen, and A. Astrup, "Effect of alginate supplementation on weight loss in obese subjects completing a 12-wk energy-restricted diet: a randomized controlled trial," American Journal of Clinical Nutrition, vol. 96, no. 1, pp. 5-13, 2012.

[7] J. A. Williams, C.-S. Lai, H. Corwin et al., "Inclusion of guar gum and alginate into A crispy bar improves postprandial glycemia in human," Journal of Nutrition, vol. 134, no. 4, pp. 886-889, 2004.

[8] N. Yavorska, "Sodium alginate-a potential tool for weight management: effect on subjective appetite, food intake, and glycemic and insulin regulation," Journal of Undergraduate Life Sciences, vol. 6, no. 1, pp. 66-69, 2012.

[9] G. G. Graham, J. Punt, M. Arora et al., "Clinical pharmacokinetics of metformin," Clinical Pharmacokinetics, vol. 50, no. 2, pp. 81-98, 2011.

[10] M. Foretz, B. Guigas, L. Bertrand, M. Pollak, and B. Viollet, "Metformin: from mechanisms of action to therapies," Cell Metabolism, vol. 20, no. 6, pp. 953-966, 2014.

[11] Z.-H. Zhang, Y.-S. Sun, H. Pang, W. L. L. Munyendo, H.-X. Lv, and S.-L. Zhu, "Preparation and evaluation of berberine alginate beads for stomach-specific delivery," Molecules, vol. 16, no. 12, pp. 10347-10356, 2011.

[12] S. C. Basak, J. Rahman, and M. Ramalingam, "Design and in vitro testing of a floatable gastroretentive tablet of metformin hydrochloride," Pharmazie, vol. 62, no. 2, pp. 145-148, 2007.

[13] H. K. Sharma, S. Lahkar, and L. Kanta Nath, "Formulation and in vitro evaluation of metformin hydrochloride loaded microspheres prepared with polysaccharide extracted from natural sources," Acta Pharmaceutica, vol. 63, no. 2, pp. 209222, 2013.

[14] J. D. Ghodake, J. S. Vidhate, D. A. Shinde, and A. N. Kadam, "Formulation and evaluation of floating microsphere containing anti-diabetic (metformin hydrochloride) drug," International Journal of PharmTech Research, vol. 2, no. 1, pp. 378-384, 2010.

[15] J. Balasubramaniam, V. U. Rao, M. Vasudha, J. Babu, and P. S. Rajinikanth, "Sodium alginate microspheres of metformin $\mathrm{HCl}$ : formulation and in vitro evaluation," Current Drug Delivery, vol. 4, no. 3, pp. 249-256, 2007. 
[16] N. Garud and A. Garud, "Preparation and in-vitro evaluation of metformin microspheres using non-aqueous solvent evaporation technique," Tropical Journal of Pharmaceutical Research, vol. 11, no. 4, pp. 577-583, 2012.

[17] R. I. El-Bagary, E. F. Elkady, and B. M. Ayoub, "Liquid chromatographic methods for the determination of vildagliptin in the presence of its synthetic intermediate and the simultaneous determination of pioglitazone hydrochloride and metformin hydrochloride," International Journal of Biomedical Science, vol. 7, no. 3, pp. 201-208, 2011.

[18] M. Przybyslawska, A. Amelian, and K. Winnicka, "Preparation of ciprofloxacin-encapsulated poly- $\varepsilon$-caprolactone microcapsules by the solvent evaporation technique," e-Polymers, vol. 13, no. 1, pp. 319-330, 2013.

[19] S. Nanda, N. Sood, B. V. K. Reddy, and T. S. Markandeywar, "Preparation and characterization of poly(vinyl alcohol)chondroitin sulphate hydrogel as scaffolds for articular cartilage regeneration," Indian Journal of Materials Science, vol. 2013, Article ID 516021, 8 pages, 2013.

[20] M. Szekalska, K. Winnicka, A. Czajkowska-Kośnik, K. Sosnowska, and A. Amelian, "Evaluation of alginate microspheres with metronidazole obtained by the spray drying technique," Acta Poloniae Pharmaceutica, vol. 72, no. 3, pp. 569-578, 2015.

[21] E. Szymańska, K. Sosnowska, W. Miltyk, M. Rusak, A. Basa, and K. Winnicka, "The effect of $\beta$-glycerophosphate crosslinking on chitosan cytotoxicity and properties of hydrogels for vaginal application," Polymers, vol. 7, no. 11, pp. 2223-2244, 2015.

[22] The European Pharmacopeia, vol. 2, Council of Europe, Strasburg, France, 6th edition, 2007.

[23] E. Szymańska and K. Winnicka, "Preparation and in vitro evaluation of chitosan microgranules with clotrimazole," Acta Poloniae Pharmaceutica, vol. 69, no. 3, pp. 509-513, 2012.

[24] P. Costa and J. M. Sousa Lobo, "Modeling and comparison of dissolution profiles," European Journal of Pharmaceutical Sciences, vol. 13, no. 2, pp. 123-133, 2001.

[25] J. Siepmann and N. A. Peppas, "Modeling of drug release from delivery systems based on hydroxypropyl methylcellulose (HPMC)," Advanced Drug Delivery Reviews, vol. 48, no. 2-3, pp. 139-157, 2001.

[26] E. Mazurek-Wadołkowska, K. Winnicka, A. CzajkowskaKośnik, U. Czyżewska, and W. Miltyk, "Application of differential scanning calorimetry in evaluation of solid state interactions in tablets containing acetaminophen," Acta Poloniae Pharmaceutica-Drug Research, vol. 70, no. 5, pp. 787-793, 2013.

[27] S. Özcan and M. Johnston, "Function and regulation of yeast hexose transporters," Microbiology and Molecular Biology Reviews, vol. 63, no. 3, pp. 554-569, 1999.

[28] D. K. Patel, R. Kumar, D. Laloo, and S. Hemalatha, "Evaluation of phytochemical and antioxidant activities of the different fractions of Hybanthus enneaspermus (Linn.) F. Muell. (Violaceae)," Asian Pacific Journal of Tropical Medicine, vol. 4, no. 5, pp. 391-396, 2011.

[29] M. Bhutkar and S. Bhise, "In vitro hypoglycemic effects of Albizzia lebbeck and Mucuna pruriens," Asian Pacific Journal of Tropical Biomedicine, vol. 3, no. 11, pp. 866-870, 2013.

[30] M. Soupioni, E. Polichroniadou, M. Tokatlidou, M. Kanellaki, and A. A. Koutinas, "Glucose uptake rate by Saccharomyces cerevisiae in the presence of promoters of alcoholic fermentation using ${ }^{14} \mathrm{C}$-labelled glucose," Biotechnology Letters, vol. 20, no. 5 , pp. 495-497, 1998.

[31] C. Reinhardt, B. Völker, H.-J. Martin, J. Kneiseler, and G. F. Fuhrmann, "Different activation energies in glucose uptake in
Saccharomyces cerevisiae DFY1 suggest two transport systems," Biochimica et Biophysica Acta (BBA)-Biomembranes, vol. 1325, no. 1, pp. 126-134, 1997.

[32] S. Lordan, T. J. Smyth, A. Soler-Vila, C. Stanton, and R. Paul Ross, "The $\alpha$-amylase and $\alpha$-glucosidase inhibitory effects of Irish seaweed extracts," Food Chemistry, vol. 141, no. 3, pp. 21702176, 2013.

[33] P. Sudha, S. S. Zinjarde, S. Y. Bhargava, and A. R. Kumar, "Potent $\alpha$-amylase inhibitory activity of Indian Ayurvedic medicinal plants," BMC Complementary and Alternative Medicine, vol. 11, article 5, pp. 1-10, 2011.

[34] N. Dekdouk, N. Malafronte, D. Russo et al., "Phenolic compounds from Olea europaea L. possess antioxidant activity and inhibit carbohydrate metabolizing enzymes in vitro," EvidenceBased Complementary and Alternative Medicine, vol. 2015, Article ID 684925, 9 pages, 2015.

[35] S. Akkarachiyasit, P. Charoenlertkul, S. Yibchok-Anun, and S. Adisakwattana, "Inhibitory activities of cyanidin and its glycosides and synergistic effect with acarbose against intestinal $\alpha$-glucosidase and pancreatic $\alpha$-amylase," International Journal of Molecular Sciences, vol. 11, no. 9, pp. 3387-3396, 2010.

[36] T. Ma, X. Sun, C. Tian, J. Luo, C. Zheng, and J. Zhan, "Enrichment and purification of polyphenol extract from Sphallerocarpus gracilis stems and leaves and in vitro evaluation of DNA damage-protective activity and inhibitory effects of $\alpha$-amylase and $\alpha$-glucosidase," Molecules, vol. 20, no. 12, pp. 21442-21457, 2015.

[37] K. Cal and K. Sollohub, "Spray drying technique. I: hardware and process parameters," Journal of Pharmaceutical Sciences, vol. 99, no. 2, pp. 575-586, 2010.

[38] S. K. Singh, P. R. Vuddanda, S. Singh, and A. K. Srivastava, "A comparison between use of spray and freeze drying techniques for preparation of solid self-microemulsifying formulation of valsartan and in vitro and in vivo evaluation," BioMed Research International, vol. 2013, Article ID 909045, 13 pages, 2013.

[39] Y. Baimark and Y. Srisuwan, "Preparation of polysaccharidebased microspheres by a water-in-oil emulsion solvent diffusion method for drug carriers," International Journal of Polymer Science, vol. 2013, Article ID 761870, 6 pages, 2013.

[40] A. Sosnik and K. P. Seremeta, "Advantages and challenges of the spray-drying technology for the production of pure drug particles and drug-loaded polymeric carriers," Advances in Colloid and Interface Science, vol. 223, article no. 1537, pp. 40-54, 2015.

[41] C. M. Silva, A. J. Ribeiro, D. Ferreira, and F. Veiga, "Insulin encapsulation in reinforced alginate microspheres prepared by internal gelation," European Journal of Pharmaceutical Sciences, vol. 29, no. 2, pp. 148-159, 2006.

[42] J. D. Clogston and A. K. Patri, "Zeta potential measurement," in Characterization of Nanoparticles Intended for Drug Delivery, S. E. McNeil, Ed., vol. 697 of Methods in Molecular Biology, pp. 63-70, 2011.

[43] R. Shaikh, T. R. Raj Singh, M. J. Garland, A. D. Woolfson, and R. F. Donnelly, "Mucoadhesive drug delivery systems," Journal of Pharmacy and Bioallied Sciences, vol. 3, no. 1, pp. 89-100, 2011.

[44] K. Ghosal and S. D. Ray, "Alginate/hydrophobic HPMC (60 M) particulate systems: new matrix for site-specific and controlled drug delivery," Brazilian Journal of Pharmaceutical Sciences, vol. 47, no. 4, pp. 833-844, 2011.

[45] S. Takka and A. Gürel, "Evaluation of chitosan/alginate beads using experimental design: formulation and in vitro characterization," AAPS PharmSciTech, vol. 11, no. 1, pp. 460-466, 2010. 
[46] S. A. Mortazavi and J. D. Smart, "An investigation into the role of water movement and mucus gel dehydration in mucoadhesion," Journal of Controlled Release, vol. 25, no. 3, pp. 197-203, 1993.

[47] K. E. Haugstad, A. G. Håti, C. T. Nordgård et al., "Direct determination of chitosan-mucin interactions using a singlemolecule strategy: comparison to alginate-mucin interactions," Polymers, vol. 7, no. 2, pp. 161-185, 2015.

[48] S. Roy, K. Pal, A. Anis, K. Pramanik, and B. Prabhakar, "Polymers in mucoadhesive drug-delivery systems: a brief note," Designed Monomers and Polymers, vol. 12, no. 6, pp. 483-495, 2009.

[49] S. J. Jackson and A. C. Perkins, "In vitro assessment of the mucoadhesion of cholestyramine to porcine and human gastric mucosa," European Journal of Pharmaceutics and Biopharmaceutics, vol. 52, no. 2, pp. 121-127, 2001.

[50] E. Szymańska, K. Winnicka, A. Amelian, and U. Cwalina, "Vaginal chitosan tablets with clotrimazole-design and evaluation of mucoadhesive properties using porcine vaginal mucosa, mucin and gelatine," Chemical and Pharmaceutical Bulletin, vol. 62, no. 2, pp. 160-167, 2014.

[51] G. P. Panizzon, F. G. Bueno, T. Ueda-Nakamura, C. V. Nakamura, and B. P. Dias Filho, "Preparation of spray-dried soy isoflavone-loaded gelatin microspheres for enhancement of dissolution: formulation, characterization and in vitro evaluation," Pharmaceutics, vol. 6, no. 4, pp. 599-615, 2014.

[52] J. P. Soares, J. E. Santos, G. O. Chierice, and E. T. Cavalheiro, "Thermal behavior of alginic acid and its sodium salt," Eclética Química, vol. 29, no. 2, pp. 53-56, 2004.

[53] J. Tuomilehto, J. Lindström, J. G. Eriksson et al., "Prevention of type 2 diabetes mellitus by changes in lifestyle among subjects with impaired glucose tolerance," The New England Journal of Medicine, vol. 344, no. 18, pp. 1343-1350, 2001.

[54] I. Ruiz-Tamayo, J. Franch-Nadal, M. Mata-Cases et al., "Noninsulin antidiabetic drugs for patients with type 2 diabetes mellitus: are we respecting their contraindications?" Journal of Diabetes Research, vol. 2016, Article ID 7502489, 9 pages, 2016.

[55] A. Y. Y. Cheng and I. G. Fantus, "Oral antihyperglycemic therapy for type 2 diabetes mellitus," Canadian Medical Association Journal, vol. 172, no. 2, pp. 213-226, 2005.

[56] G. Wilcox, "Insulin and insulin resistance," The Clinical Biochemist Reviews, vol. 2, no. 3, pp. 19-39, 2005.

[57] S. Ou, K.-C. Kwok, Y. Li, and L. Fu, "In vitro study of possible role of dietary fiber in lowering postprandial serum glucose," Journal of Agricultural and Food Chemistry, vol. 49, no. 2, pp. 1026-1029, 2001.

[58] G. López, G. Ros, F. Rincón, M. J. Periago, M. C. Martínez, and J. Ortuño, "Relationship between physical and hydration properties of soluble and insoluble fiber of artichoke," Journal of Agricultural and Food Chemistry, vol. 44, no. 9, pp. 2773-2778, 1996.

[59] S. Busti, P. Coccetti, L. Alberghina, and M. Vanoni, "Glucose signaling-mediated coordination of cell growth and cell cycle in Saccharomyces cerevisiae," Sensors, vol. 10, no. 6, pp. 6195-6240, 2010.

[60] A. Roy, A. D. Dement, K. H. Cho, and J.-H. Kim, "Assessing glucose uptake through the yeast hexose transporter 1 (Hxtl)," PLoS ONE, vol. 10, no. 3, Article ID e0121985, 2015.

[61] G. L. Kellett, E. Brot-Laroche, O. J. Mace, and A. Leturque, "Sugar absorption in the intestine: the role of GLUT2," Annual Review of Nutrition, vol. 28, no. 3, pp. 35-54, 2008.
[62] J. Zhang, C. Tiller, J. Shen et al., "Antidiabetic properties of polysaccharide- and polyphenolic-enriched fractions from the brown seaweed Ascophyllum nodosum," Canadian Journal of Physiology and Pharmacology, vol. 85, no. 11, pp. 1116-1123, 2007.

[63] Y. Sharifuddin, Y.-X. Chin, P.-E. Lim, and S.-M. Phang, "Potential bioactive compounds from seaweed for diabetes management," Marine Drugs, vol. 13, no. 8, pp. 5447-5491, 2015.

[64] H. Ali, P. J. Houghton, and A. Soumyanath, " $\alpha$-Amylase inhibitory activity of some Malaysian plants used to treat diabetes; with particular reference to Phyllanthus amarus," Journal of Ethnopharmacology, vol. 107, no. 3, pp. 449-455, 2006.

[65] Z. Ahmad, K. F. Zamhuri, A. Yaacob et al., "In Vitro antidiabetic activities and chemical analysis of polypeptide- $\mathrm{k}$ and oil isolated from seeds of Momordica charantia (bitter gourd)," Molecules, vol. 17, no. 8, pp. 9631-9640, 2012.

[66] C. A. Tarling, K. Woods, R. Zhang et al., "The search for novel human pancreatic $\alpha$-amylase inhibitors: high-throughput screening of terrestrial and marine natural product extracts," ChemBioChem, vol. 9, no. 3, pp. 433-438, 2008. 

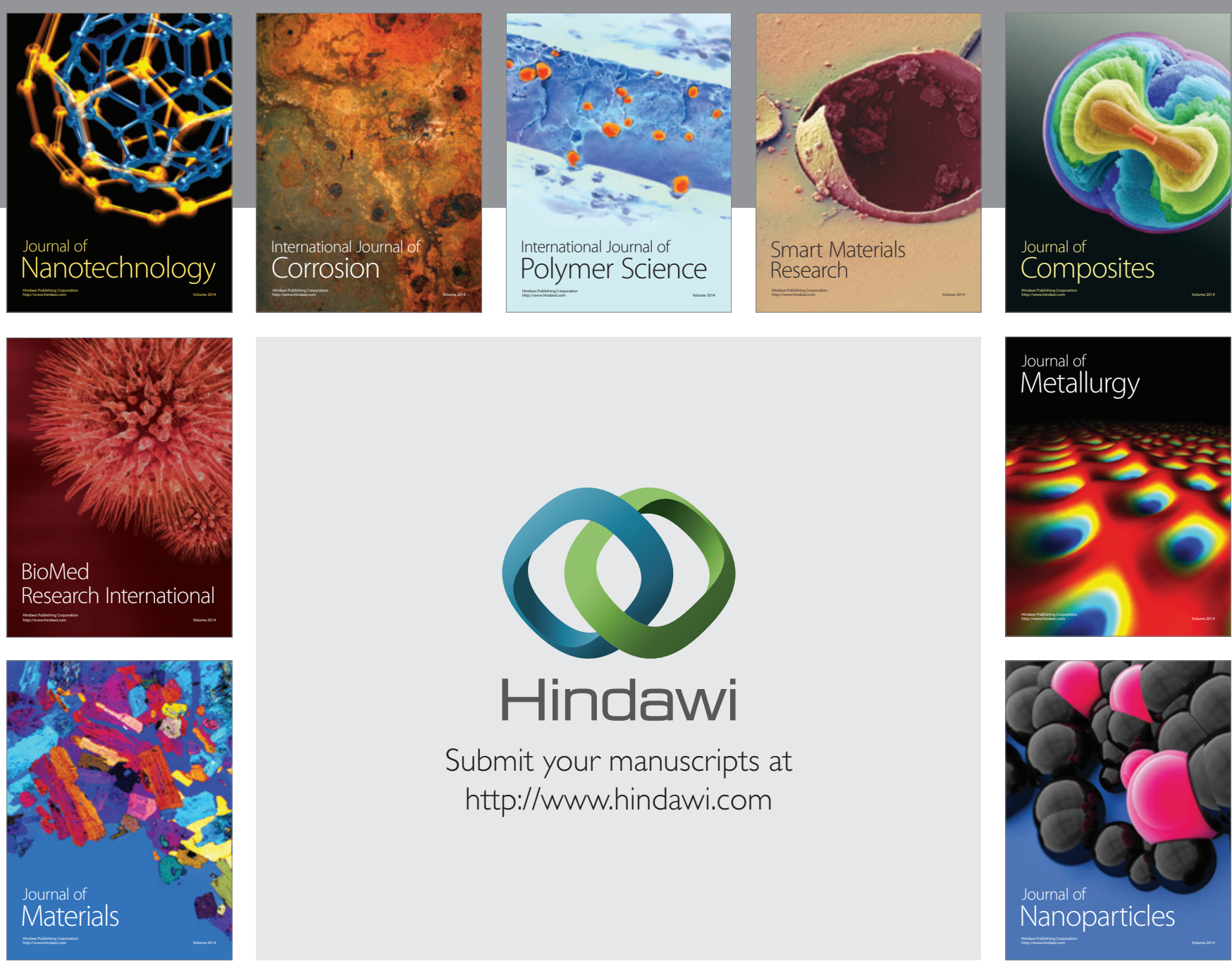

\section{Hindawi}

Submit your manuscripts at

http://www.hindawi.com

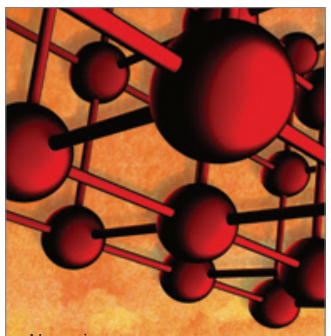

Materials Science and Engineering
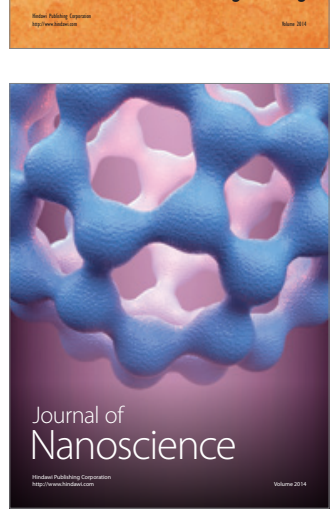
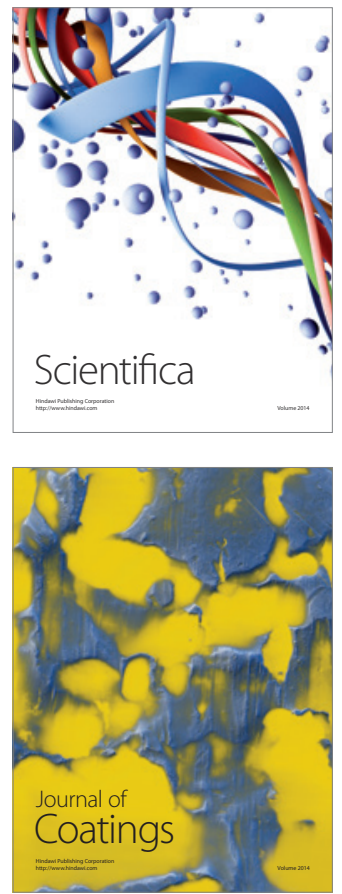
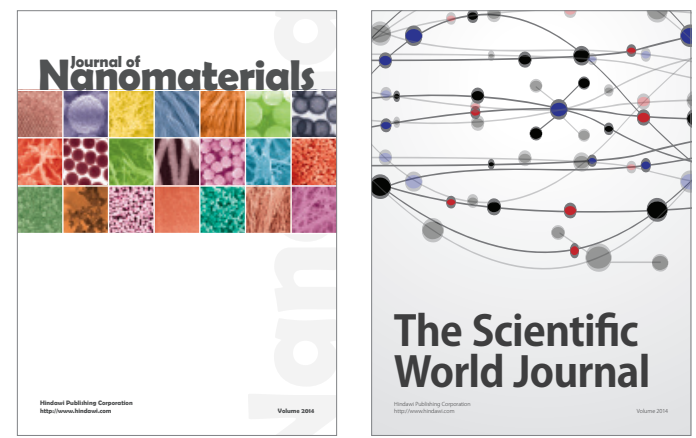

The Scientific World Journal
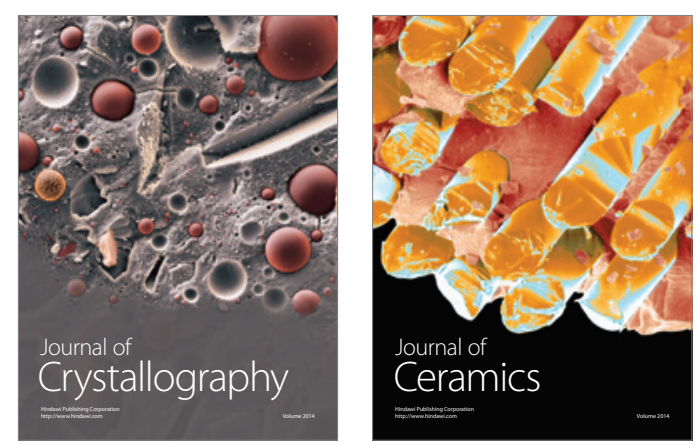
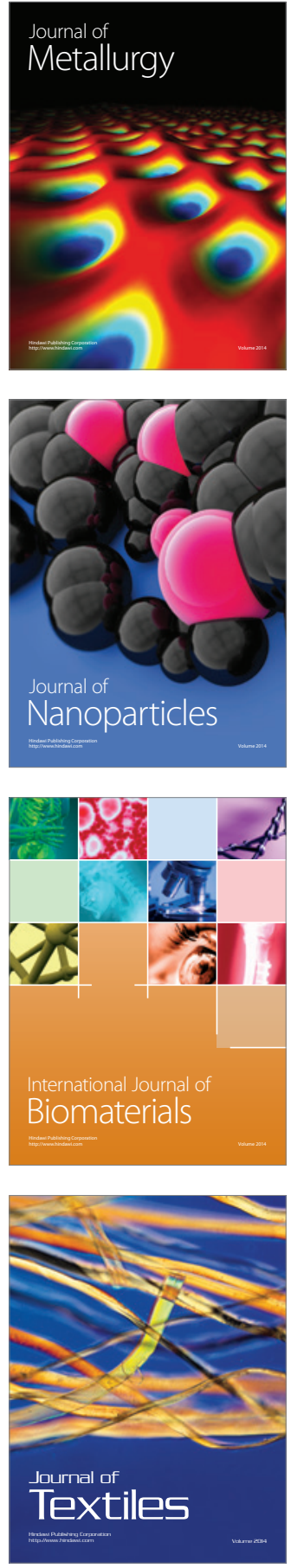